\title{
Brucella ceti infection in dolphins from the Western Mediterranean sea
}

\author{
Marcos Isidoro-Ayza ${ }^{1 \dagger}$, Nazareth Ruiz-Villalobos ${ }^{2 \dagger}$, Lola Pérez ${ }^{1}$, Caterina Guzmán-Verri ${ }^{2}$, Pilar M Muñoz ${ }^{3}$, \\ Fernando Alegre ${ }^{4}$, Montserrat Barberán ${ }^{3}$, Carlos Chacón-Díaz 2,5 Esteban Chaves-Olarte ${ }^{2,5}$, Rocio González-Barrientos ${ }^{6}$, \\ Edgardo Moreno ${ }^{2,7}$, José María Blasco ${ }^{3}$ and Mariano Domingo ${ }^{1,8^{*}}$
}

\begin{abstract}
Background: Brucella ceti infections have been increasingly reported in cetaceans. Brucellosis in these animals is associated with meningoencephalitis, abortion, discospondylitis', subcutaneous abscesses, endometritis and other pathological conditions $B$. ceti infections have been frequently described in dolphins from both, the Atlantic and Pacific Oceans. In the Mediterranean Sea, only two reports have been made: one from the Italian Tyrrhenian Sea and the other from the Adriatic Sea.

Results: We describe the clinical and pathological features of three cases of $B$. ceti infections in three dolphins stranded in the Mediterranean Catalonian coast. One striped dolphin had neurobrucellosis, showing lethargy, incoordination and lateral swimming due to meningoencephalitis, A B. ceti infected bottlenose dolphin had discospondylitis, and another striped dolphin did not show clinical signs or lesions related to Brucella infection. A detailed characterization of the three $B$. ceti isolates was performed by bacteriological, molecular, protein and fatty acid analyses.

Conclusions: All the B. ceti strains originating from Mediterranean dolphins cluster together in a distinct phylogenetic clade, close to that formed by B. ceti isolates from dolphins inhabiting the Atlantic Ocean. Our study confirms the severity of pathological signs in stranded dolphins and the relevance of $B$. ceti as a pathogen in the Mediterranean Sea.
\end{abstract}

Keywords: Brucella ceti, Cetacean, Neurobrucellosis, Discospondylitis, Mediterranean sea

\section{Background}

After the first descriptions of Brucella infections in dolphins and seals and the definition of Brucella ceti and Brucella pinnipedialis as two new species within the genus [1-3], there has been an increasing recognition of brucellosis in marine mammals (see [4] and [5] for recent reviews). Brucella strains from marine mammal origin have been isolated from humans [6]. Antibodies against Brucella have been detected in 28 out of 42 cetacean species investigated, and $B$. ceti has been isolated

\footnotetext{
* Correspondence: mariano.domingo@cresa.uab.cat

${ }^{\dagger}$ Equal contributors

'Departament de Sanitat i Anatomia Animal, Facultat de Veterinària Universitat Autònoma de Barcelona (UAB), and Servei de Diagnòstic de Patologia Veterinària, Facultat de Veterinària, Universitat Autònoma de Barcelona (UAB), 08193, Bellaterra, Barcelona, Spain

${ }^{8}$ Centre de Recerca en Sanitat Animal (CReSA), UAB-IRTA, 08193, Bellaterra, Cerdanyola del Vallès, Barcelona, Spain

Full list of author information is available at the end of the article
}

from 10 of these species [5]. B. ceti infection in cetaceans is associated to meningoencephalomyelitis [1,3,7-9], abortion $[1,2]$, discospondylitis, subcutaneous abscesses, endometritis, and a wide range of other pathological conditions $[4,5,10]$. However, with the exception of the striped dolphin (Stenella coeruleoalba) [1,3-5,9-13] the proportion of other cetacean species showing clinicopathological signs associated with brucellosis is low, suggesting that most of these infected animals overcome clinical disease, eventually remaining as Brucella carriers and shedders.

Presumptive Brucella infections in Western Mediterranean Sea dolphins was first established by serology in two striped dolphins and one bottlenose dolphin (Tursiops truncatus) stranded on the Mediterranean Catalonian coast [14]. Recently, Brucella strains were isolated from striped dolphins in the Tyrrhenian and Adriatic Seas [11,15]. Here, we describe the clinical and pathological features of three 
cases of brucellosis in dolphins stranded on the Mediterranean Catalonian coast, and provide detailed information on the phenotypic and molecular characterization of these three $B$. ceti isolates.

\section{Methods}

Dolphin stranding and serological, pathological and bacteriological examinations

Two striped dolphins (N-372/09, N-301/12) and one bottlenose dolphin (N-275/12) reacting positive in standard Rose Bengal Test (RBT), performed according to standard procedures [16] were included in this study. The relevant animal and stranding data are shown in Table 1. At the time of necropsy all three dolphin carcasses were in a good preservation state (2 in a scale of 1 -very good- to 5 -poor-). Gross pathological studies were performed in the three dolphins and complete sets of organs and tissues for each animal were preserved in $10 \%$ buffered formalin and processed for histopathological examination and immunohistochemical detection of Cetacean Morbillivirus (CeMV) as described previously [17]. Selected samples of brain tissue and spleen from the three dolphins were also examined immunohistochemically using an anti-B. melitensis $16 \mathrm{M}$ polyclonal rabbit antiserum and avidin-biotin peroxidase system as described elsewhere $[7,12]$.

Tissue samples of two dolphins (N-275/12 and N-301/ 12) were collected at the time of necropsy and submitted for bacteriological examination (Table 1). Tissues of the third dolphin (S. coeruleoalba, N-372/09), frozen at $-80^{\circ} \mathrm{C}$ since 2009, were defrosted and submitted also to bacteriological studies, but cerebrospinal fluid (CSF) was not available in this case. Swabs taken at necropsy were each smeared in at least two plates of both Farrell's [18] and CITA [19] culture media. The remaining necropsy samples were homogenized under sterile conditions in the minimum amount possible of sterile buffered saline (PBS pH 6.8) in a Stomacher unit (Seward Medical, Worthing, UK), and $0.5 \mathrm{~mL}$ of each tissue homogenate seeded also on at least two plates of each selective culture medium. The plates were checked for growth after $5-8$ days of incubation at $37^{\circ} \mathrm{C}$ both in air and $10 \%$ $\mathrm{CO}_{2}$ atmospheres. Brucella colonies were identified by colonial morphology and standard typing procedures $[20,16]$. One culture was considered as positive when at least one Brucella colony forming unit (CFU) was isolated. The suspected Brucella colonies isolated were further identified and characterized by molecular and chemical methods (see below).

\section{Control strains}

The following strains obtained from the CITA and from PIET/CIET strain collections were used as controls for molecular studies: B. ceti Atlantic dolphin type (B14/94), B. ceti Atlantic porpoise type (B1/94), B. ceti Cantabric Sea isolate from $S$. coeruleoalba stranded in Northern Spain (C1), B. pinnipedialis seal type (B2/94), Brucella abortus 2308 (biovar 1 virulent reference strain), $B$. abortus S19 (biovar 1 reference vaccine strain), Brucella melitensis Rev1 (biovar 1 reference vaccine strain), Brucella suis (S2 biovar 1 ), B. canis (CR206-10; Costa Rica isolate), B. neotomae $5 \mathrm{~K} 33$ (reference strain), Brucella ovis PA (virulent reference strain) and Brucella microti (CCM4915, reference strain).

\section{Molecular studies}

Brucella DNA samples from each isolate and control strains were extracted with DNeasy Blood \& Tissue kit

Table 1 Biological data of Brucella ceti infected Mediterranean dolphins

\begin{tabular}{|c|c|c|c|c|}
\hline Identification & $\begin{array}{l}\text { Place, coordinates and } \\
\text { date of stranding }\end{array}$ & Pathological diagnoses (Macro/Micro) & $\begin{array}{l}\text { Tissues sampled for bacteriological } \\
\text { examination }\end{array}$ & $\begin{array}{l}\text { B. ceti strain } \\
\text { isolated from }\end{array}$ \\
\hline $\mathrm{N}-372 / 09$ & Salou, Spain & \multirow{3}{*}{$\begin{array}{l}\text { Non-suppurative encephalitis by CeMV. RT-PCR } \\
\text { and IHC for CeMV both positive only in CNS }\end{array}$} & \multirow{3}{*}{$\begin{array}{l}\text { Encephalon, spleen, diaphragmatic and } \\
\text { preescapular lymph nodes, lung }\end{array}$} & bmarMR26 \\
\hline $\begin{array}{l}\text { Stenella } \\
\text { coeruleoalba }\end{array}$ & $(41.0733,1.1343)$ & & & Spleen \\
\hline $\begin{array}{l}\text { Male, } 1.94 \mathrm{~m}, \\
74.5 \mathrm{Kg}\end{array}$ & $\begin{array}{l}\text { Found alive } \\
\text { Sept 11th-2009 }\end{array}$ & & & \\
\hline$N-275 / 12$ & Badalona, Spain & \multirow{2}{*}{$\begin{array}{l}\text { Mycotic pyogranulomatous-necrotizing } \\
\text { meningoencephalomyelitis }\end{array}$} & \multirow{4}{*}{$\begin{array}{l}\text { Encephalon, CSF (swab from lateral } \\
\text { ventricle), vertebral abscess (swab), } \\
\text { spleen. }\end{array}$} & bmarMR25 \\
\hline $\begin{array}{l}\text { Tursiops } \\
\text { truncatus }\end{array}$ & $(41.4458,2.2507)$ & & & $\begin{array}{l}\text { Vertebral } \\
\text { abscess }\end{array}$ \\
\hline \multirow[t]{2}{*}{ Male 3 m } & \multirow[t]{2}{*}{$\begin{array}{l}\text { Found dead } \\
\text { 7May 23rd-2012 }\end{array}$} & $\begin{array}{l}\text { Chronic, severe, focally extensive, suppurative } \\
\text { discospondylitis }\end{array}$ & & \\
\hline & & RT-PCR and IHC for CeMV negative & & \\
\hline$N-301 / 12$ & Cunit, Spain & \multirow{3}{*}{$\begin{array}{l}\text { Non-suppurative meningoencephalitis. RT-PCR } \\
\text { and IHC for CeMV negative }\end{array}$} & \multirow{3}{*}{$\begin{array}{l}\text { Encephalon, spleen, diaphragmatic } \\
\text { lymph node, lung }\end{array}$} & bmarMR24 \\
\hline $\begin{array}{l}\text { Stenella } \\
\text { coeruleoalba }\end{array}$ & $(41.1931,1.6360)$ & & & Encephalon \\
\hline $\begin{array}{l}\text { Female, } 1.84 \mathrm{~m}, \\
54.5 \mathrm{Kg}\end{array}$ & $\begin{array}{l}\text { Found alive } \\
\text { June } 3 \text { rd-2012 }\end{array}$ & & & \\
\hline
\end{tabular}


from QIAGEN ${ }^{\oplus}$, and stored at $-70^{\circ} \mathrm{C}$ until used. The three Mediterranean dolphin isolates were identified as $B$. ceti using the multiplex PCR as described elsewhere [21]. DNA samples from these isolates and the marine control strains were also tested by PCR-RFLP of $o m p 2 b$ locus [22] and by multiplex PCR using the following two pairs of primers: TCA ACT GCG TGA ACA ATG CT (f) / GCG GGC TCT ATC TCA AGG TC (r), and CGT CAA CTC GCT GGC CAA GAG (f) / GCA GGA GAA CCG CAA CCT AA (r). Multiple loci variable number of tandem repeats (MLVA-16) analysis of Brucella species and strains was performed as described previously [23-26]. The basic protocol for MLVA-16 was slightly modified to use DreamTaq ${ }^{\text {TM }}$ PCR Master Mix (Fermentas ${ }^{\circ}$ ). Amplicon analysis was performed on the ChemiDoc Gel Documentation System XRS, BioRad ${ }^{\circledR}$ using the Quantity One ${ }^{\oplus}$ software, which allowed molecular size determination of amplicons. Brucella control strains were used for validation $[12,23,26]$. The profiles were entered in the database MLVA-NET for the corresponding analysis [27].

\section{Mass spectrometry analysis of Brucella protein extracts} For MALDI-TOF studies, the three B. ceti isolates and all control strains were grown in trypticase soy agar plates for four days in the presence or in the absence of $\mathrm{CO}_{2}$ (as required) following modifications of previous protocols $[16,18,28]$. For each bacterial strain, three clearly separated colonies were suspended in a $1.5 \mathrm{ml}$ Eppendorf tube containing $1 \mathrm{ml}$ of ultrapure distilled water, and centrifuged at 14,000 rpm for $5 \mathrm{~min}$. Then, the bacterial pellet was thoroughly resuspended in $300 \mu \mathrm{L}$ of water. After this, $700 \mu \mathrm{L}$ of absolute ethanol were added, the suspension mixed in a vortex, let rest for five minutes at room temperature and centrifuged at $14,000 \mathrm{rpm}$ for 5 minutes. The bacterial pellet was resuspended in $250 \mu \mathrm{L}$ of water and directly sonicated in the Eppendorf tube with the aid of a titanium micro tip, at room temperature for 2 minutes. Nine hundred $\mu \mathrm{L}$ of absolute ethanol were added and the extract dried to completeness in a speed-vac centrifuge at $45^{\circ} \mathrm{C}$ for $\sim 2.5$ hours. Fifty $\mu \mathrm{L}$ of $70 \%$ formic acid were added to suspend the dried pellet, mixed thoroughly by pipetting and then $50 \mu \mathrm{L}$ of acetonitrile were added and mixed. The extract was centrifuged at 14,000 rpm for 5 minutes and the supernatant transferred into a clean tube. In order to select optimal conditions for mass spectrometer analysis, several dilutions of the extract were tested. A volume of $0.5 \mu \mathrm{L}$ of each dilution was spotted onto a steel Opti-TOF 384 plate target (ABSciex) and air-dried at room temperature. The spot sample was overlaid with $0.5 \mu \mathrm{L}$ of matrix solution (saturated solution of alphacyano-4-hydroxy-cinnamic acid) in organic solvent (50\% acetonitrile and $2.5 \%$ trifluoroacetic acid) and air-dried.
The samples were analyzed in a MALDI-TOF on an Applied Biosystems 4800 Plus mass spectrometer. Spectra were acquired in linear positive mode, using a laser intensity of 3,800 and 500 shots/spectrum, in the $\mathrm{m} / \mathrm{z}$ range 2,000 to 11,000 , after external MS calibration with CalMix-5 standards (ABSciex) spotted on the same plate. Spectra were visualized using Data Explorer v.4.9 (Applied Biosystems).

\section{Gas chromatographic analysis of fatty acid methyl esters}

The three $B$. ceti isolates and all control strains were grown as described above. For each bacterial strain, 75 clearly separated colonies were chosen from three plates and placed in a sealed glass tube. Saponification of the samples and processing for total fatty acid methyl ester determination were carried out according to the MIDI instruction manual of Technical Note \#101 (MIS, MIDI Inc., Newark, DE). Analysis was performed by gas chromatography (Agilent Technologies 6850) using a $25 \mathrm{~m} \mathrm{x}$ 0,2 mm cross linked phenyl-methyl silicone fused silica capillary column HP 19091B-102 (Agilent Technologies Inc., Santa Clara, CA). A binary matrix was generated using the fatty acid profile of the tested strains.

\section{Phylogenetic analysis and cladograms}

Dendrograms based on the retention time of the fatty acid methyl esters and on the protein masses detected were constructed using an Agglomerative hierarchical clustering (AHC) algorithm, using Microsoft ${ }^{\oplus}$ Excel 2000/XLSTAT ${ }^{\odot}$-Pro (Version 4.07, 2013, Addinsoft, Inc., Brooklyn, NY, USA). Proximities were calculated using Squared Euclidean Distance, and aggregation was calculated using the unweighted pair-group average method. MLVA 16 phylogenetic trees based on differences in MLVA-16 was built according to the procedures described in the Brucella MLVA database [27].

\section{Results}

\section{Clinical and pathological findings}

The main biopathological features of the three Mediterranean dolphins from which $B$. ceti strains were isolated are summarized in Table 1.

Striped dolphin N-301/12 was found stranded alive, showing uncoordinated swimming, with circling and severe lateralization, needing continuous support (Figure 1A). This dolphin died four days after stranding, in spite of the supportive medical care. Episodes of tonic-clonic seizures were observed shortly before death. At necropsy, this animal showed a good body condition. No significant gross lesions were observed, apart from a moderate amount of subcutaneous oedema in the cranial region of the trunk, and multiple erosions of the tongue epithelium. A moderate infestation of the caudal blubber by larval forms of the tapeworm Phyllobothrium delphini and bile and pancreatic 

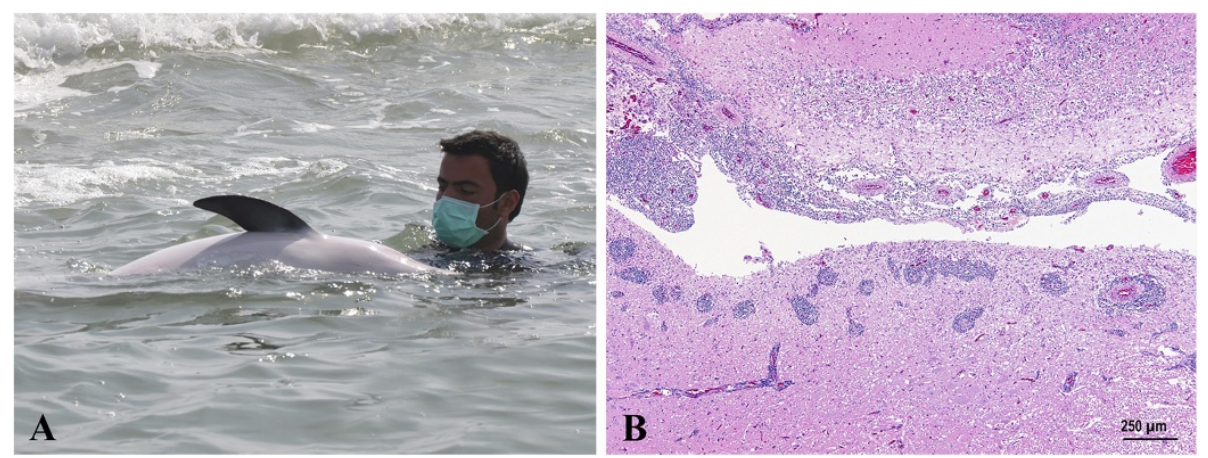

Figure 1 Striped dolphin, case N-301/12. A. Dolphin with clinical signs of neurobrucellosis, showing lateralization when swimming and inability to maintain equilibrium and flotation. The dolphin needed continuous holding and support. $\mathbf{B}$. Histopathologic section of the brain from the same case. Thick perivascular infiltrates mainly composed of lymphocytes, plasma cells and macrophages are seen affecting leptomeninges, the neuropil surrounding the fourth ventricle and the choroid plexus (H\&E)

ducts by trematodes of the genus Campula were observed. These are common parasites of striped dolphins. Histologically, the most relevant finding was a severe, diffuse, chronic, non-suppurative, meningoencephalomyelitis. The inflammatory process affected the leptomeninges, and the subependymal neuropil (periventriculitis), forming thick perivascular cuffs that shallowly penetrated into the underlying grey and white matter (Figure $1 \mathrm{~B}$ ). The process was more severe in cerebellum, brainstem, spinal cord and medulla oblongata and with less involvement of the cerebral cortex. The inflammatory infiltrate was composed of a large number of lymphocytes and plasma cells and a lesser number of macrophages. A similar inflammatory infiltrate was observed in the choroid plexus (choroiditis) as well as in the dorsal and ventral cervical nerve roots (radiculitis). All studied sections of the nervous system showed variable degrees of gliosis, satellitosis with formation of glial nodules, spongiosis and perivascular oedema.

Small, multifocal, randomly distributed, non-suppurative inflammatory infiltrates were found in the liver and kidney. In addition, a small focus of granulomatous and necrotizing lymphadenitis was seen in the mesenteric lymph node. These lesions were probably associated to parasitic migrations. No other relevant microscopical findings were found in examined tissues. Brucella antigens were not detected by IHC in CNS. RT-PCR for CeMV resulted negative in all the investigated tissues.

The bottlenose dolphin (N-275/12) was found dead. Gross external examination revealed that this dolphin was in a good body condition. Several 'Tattoo'-like lesions measuring $2-4 \mathrm{~cm}$ in diameter were observed on the skin of the left maxilla. A hard spherical mass of approximately $18 \mathrm{~cm}$ in diameter was found in the caudal peduncle. The skin was unaffected at this site (Figure 2A). On radiographs the mass was characterized as a marked bone proliferation rising from the periosteum of two consecutive coccygeal vertebrae generating ankylosis of the implicated joint (Figure 2B). A longitudinal section (Figure 2C) showed a chronic, severe, focally extensive and suppurative disco-spondylitis with marked disruption of the adjacent soft tissues (skeletal muscle fascicles, tendons and fascia). Histopathology from this lesion was not performed. In the CNS, a slightly increased amount of CSF was noticed at the lateral ventricles. After pre-fixation, the brain was sliced. At that time, poorly demarcated, bilateral areas of malacia where identified in the area of the nucleus caudatus. A third focus of malacia was disclosed in the area of the nucleus accumbens of the left hemisphere. Microscopically, there was a pyogranulomatous and necrotizing meningoencephalomyelitis and radiculitis caused by the fungus Cunninghamella bertholletiae that has been described in detail elsewhere [29]. No other significant lesions were found at necropsy in this dolphin. Tissues tested by RT-PCR for CeMV yielded negative results. IHC for Brucella yielded negative results at CNS. The coccygeal diskospondylitic lesion was not investigated by IHC.

Striped dolphin N-372/09 was found alive showing lethargy, incoordination and lateral swimming. The animal died before the rescue protocol could be initiated. At necropsy, no significant macroscopic lesions were observed in this dolphin, except for the absence of content in the stomach cavities. Moderate infestation by the common larval forms of the tapeworms Phyllobothrium delphini and Monorygma grimaldi were also observed in the caudal blubber and the peritoneal cavity respectively. Histopathological examination revealed chronic, nonsuppurative encephalitis as the main pathological sign. Immunohistochemical (IHC) staining for CeMV detected viral antigen at the Central Nervous System (CNS) of this dolphin. This result was confirmed by a CeMV positive RT-PCR in CNS tissue. Consequently, this case was diagnosed as a CNS-localized chronic CeMV infection [30]. 


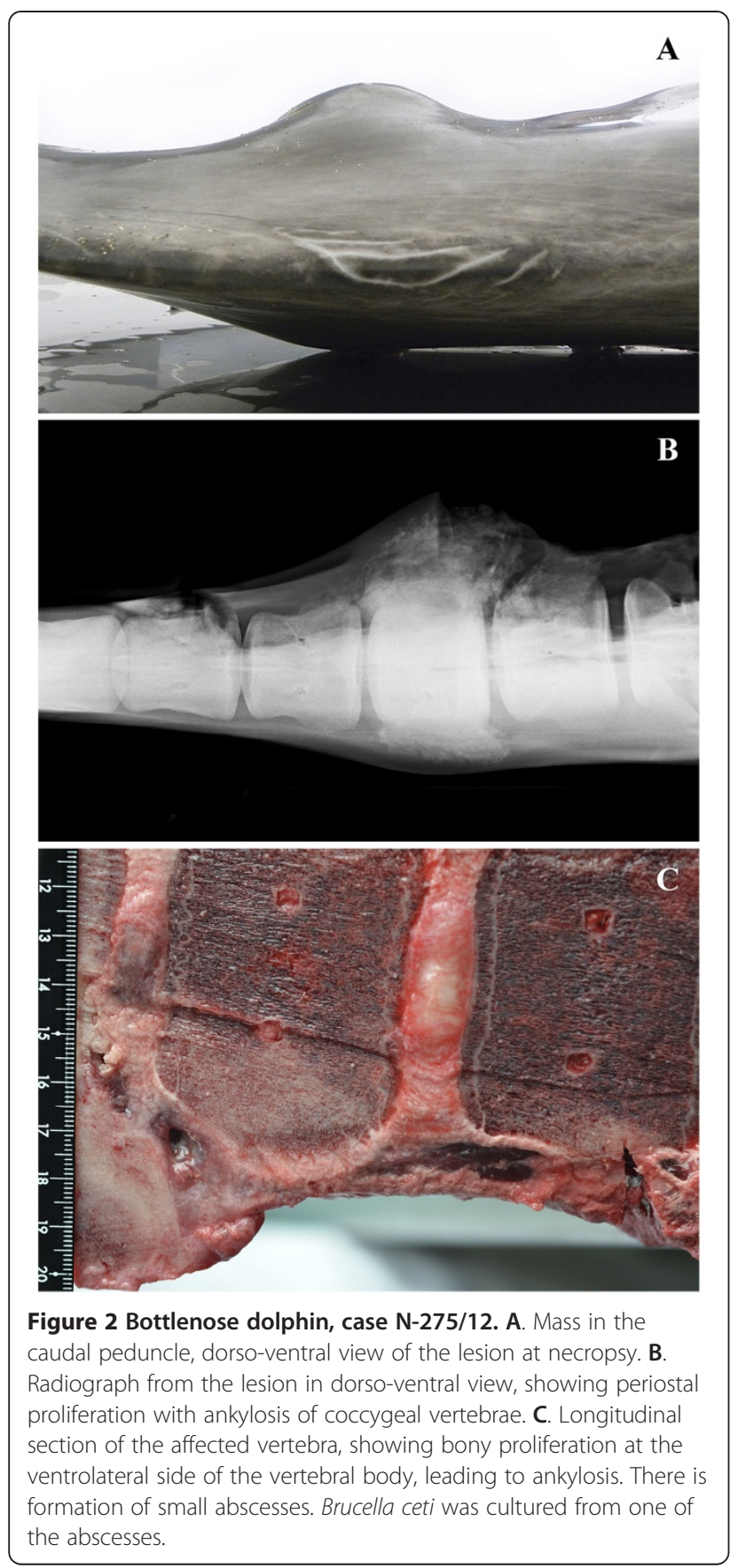

IHC for Brucella antigens showed positive staining in cytoplasm of cells inside splenic lymphoid follicles (Figure 3).

\section{Bacteriological findings}

Bacterial isolates identified as Brucella strains were obtained in high numbers from the spleen (N-372/09), vertebral abscess (N-275/12) and brain (N-301/12), respectively. The strains were isolated in the presence and absence of $\mathrm{CO}_{2}$ and selective culture media with the exception of

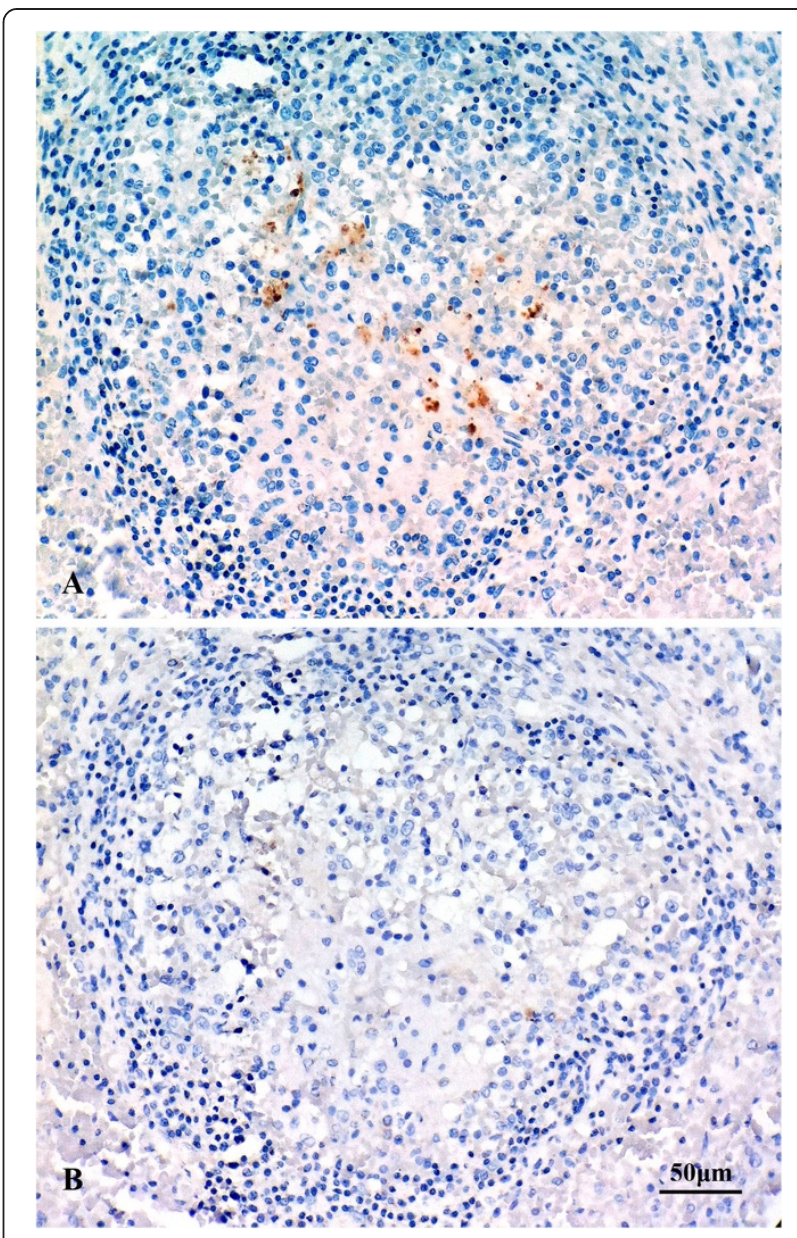

Figure 3 Immunohistochemical staining of Brucella, striped dolphin (case 372/09), spleen section. A. Section incubated with specific polyclonal antiserum to Brucella melitensis. Positivity was found in cytoplasm of cells within lymphoid follicles. B. Parallel section of the same tissue incubated with control negative antiserum. Haematoxylin counterstain.

strain from case $\mathrm{N}-301 / 12$, whose growth was inhibited on Farrell's medium. The isolated strains were not capnophilic, were positive for the oxidase and urease tests, and displayed a smooth type, agglutinating with both anti-A and anti-M mono-specific sera. The strains were as well lysed by the Iz but not the $\mathrm{Tb}, \mathrm{Wb}$ and $\mathrm{R} / \mathrm{C}$ phages, and grew on standard concentrations of both thionin and basic fuchsin. The three Mediterranean isolates were identified as $B$. ceti using the multiplex PCR. They were named as bmarMR24 (isolated from case N-301/12), bmarMR25 (from case N275/12) and bmarMR26 (from case 372/09).

\section{MLVA16, protein and fatty acid polymorphisms and phylogeny}

Fatty acid and protein molecular phenotyping are well recognized methods for typing bacteria and have been used extensively to differentiate bacteria, including Brucella strains $[24,31,32]$. The MLVA16 respective sizes for 
the analysed strains, the protein molecular weight peaks determined by MALDI-TOF and the retention times of the fatty acid methyl ester peaks determined by GLC of the strains studied are presented respectively in Additional file 1: Tables S1, Additional file 2: Table S2, and Additional file 3: Table S3. Dendrograms built on the basis of MALDI-TOF analysis demonstrated that the three $B$. ceti Mediterranean isolates clustered together in a distinct clade, close to the Atlantic dolphin type B14/94 strain (Figure 4A). However, on the basis of fatty acids (Figure 4B), they clustered with both $B$. ceti porpoise type B1/94 and B. ceti Atlantic dolphin type B14/ 94 strains. In spite of this, all B. ceti strains remained as a separate cluster from B. pinnipedialis seal B2/94 strain and other brucellae from terrestrial animals.

The PCR-RFLP of the omp $2 b$ locus confirmed also the close relationship of the three Mediterranean isolates of B. ceti, resulting in a common haplotype identical in all strains, irrespective of their geographic origin (Figure 5A). Similarly, the multiplex PCR using two primer pairs identified the Mediterranean isolates as similar to the Atlantic dolphin type B. ceti B14/94 strain (Figure 5B). The MLVA16 phylogenetic analysis showed that the three $B$. ceti Spanish Mediterranean strains clustered together in a
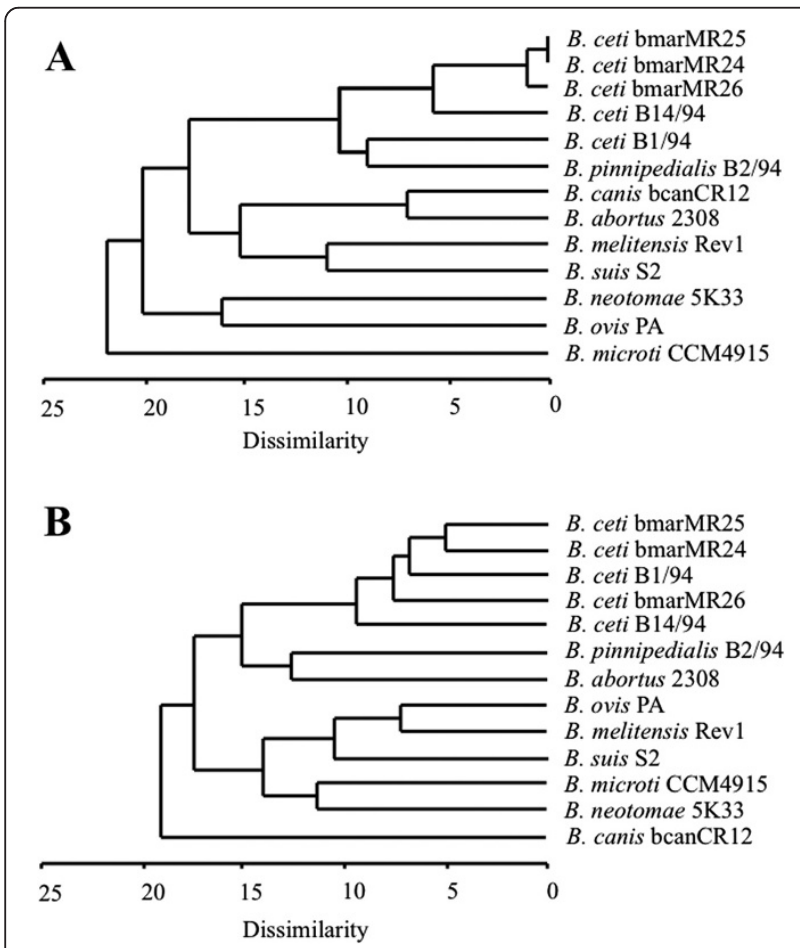

Figure 4 Dendrograms based on MALDI-TOF analysis of protein molecular weight $(A)$ and gas liquid chromatography analysis of the fatty acid methyl esters (B) of different Brucella extracts. Notice that in " $\mathrm{A}$ " the three Mediterranean strains cluster together in a single group; while in " $\mathrm{B}$ " they are intertwined with a $B$. ceti isolate from a striped dolphin from the Atlantic Ocean.

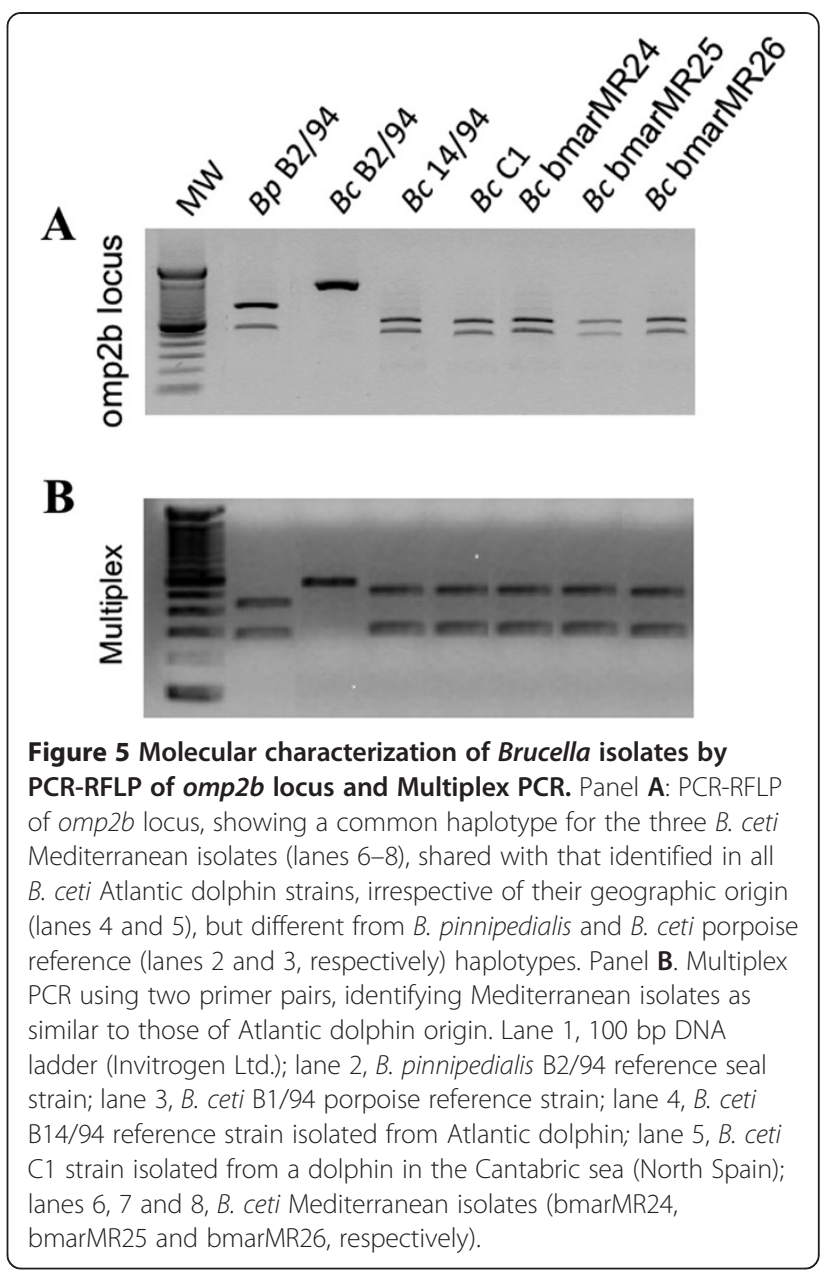

distinct clade together with the two reported B. ceti isolated in the Mediterranean Italian littoral [15] and close to the Atlantic A1 dolphin cluster (Figure 6). The distinct topology of the Mediterranean B. ceti isolates is maintained even when a comprehensive phylogenetic analysis against the complete Brucella MLVA16 base data is performed (Figure 7 ). As expected, the $B$ ceti Mediterranean isolates MLVA 16 patterns were identical to strains previously typed by MLSA as ST 26.

\section{Discussion}

During the last decade $B$. ceti strains have been isolated from stranded dolphins of both the Atlantic and Pacific Oceans [5]. Information about B.ceti strains from the Mediterranean Sea is scarce. Recently, a B. ceti strain showing phenotypic characteristics of Atlantic B. ceti strains was isolated from a striped dolphin in the Tyrrhenian littoral of Italy [11]. Also, two other B. ceti strains have been characterized from the Italian Southern Apulian Coast [15]. MLVA analysis of the two isolates assigned them to a novel genotype within cluster A. Here we confirm and extend these observations, endorsing the 


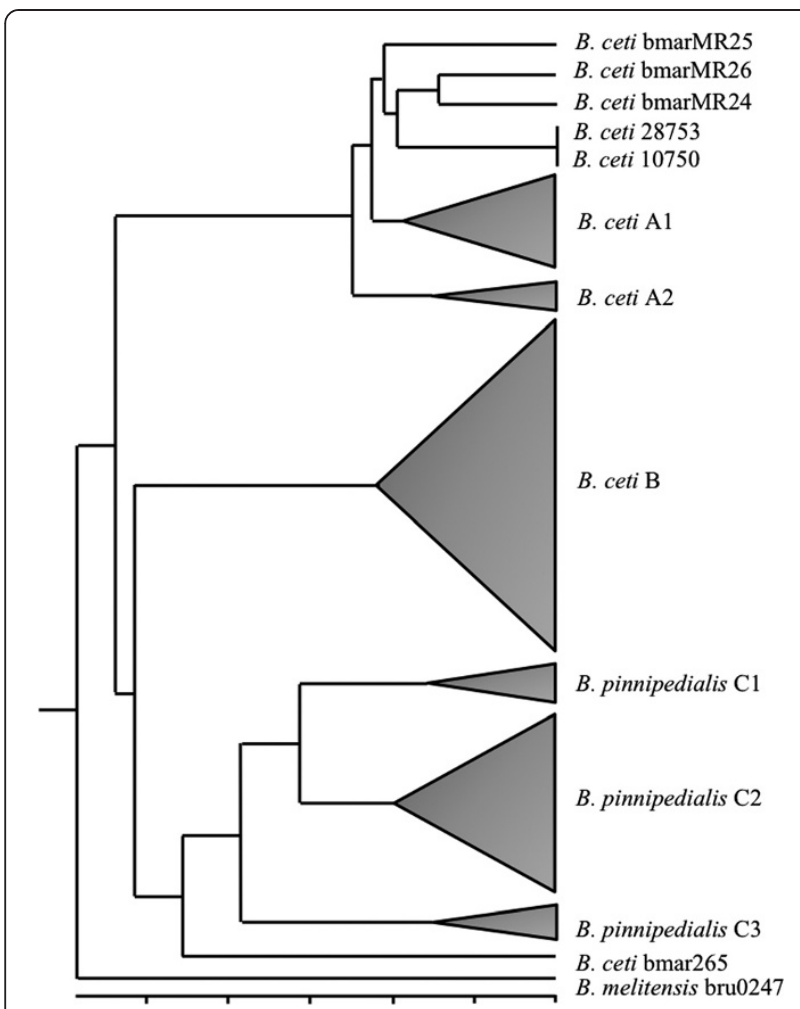

Figure 6 Cladogram based on MLVA16 analysis of Brucella isolates from marine mammals (http://mlva.upsud.fr/brucella/). The dispersion of the various Brucella strains is depicted as cones proportional to the number of strains analyzed. Notice than the five B. ceti Mediterranean strains (three from this work and two reported by Garofolo et al. [15]) cluster together in a single group in a clade close to the Atlantic isolates (A1 and $A 2)$, and far from the $B$. ceti porpoise type (B) and B. pinnipedialis (C1, C2, C3). B. ceti bmar265 (human isolate from New Zealand) does not correspond to the B. ceti group and it is ST27. B. melitensis was used as an out-group for the analysis.

presence of $B$. ceti infecting and causing pathology in at least two dolphin species (S. coeruleoalba and T. truncatus) inhabiting the Mediterranean Sea. The multilocus sequence analysis of these three $B$. ceti Mediterranean strains indicates that they also belong to the dolphin type of the ST26 cluster.Up to now, all B. ceti Mediterranean strains stem in a separate branch from the main MLVA16 A1 and A2 clusters of $B$. ceti isolates from dolphins inhabiting the Atlantic Ocean. Although the number of analysed Mediterranean $B$. ceti strains by MLVA16 is still low to draw a definitive branching order, the taxonomical position of these newly defined strains [11] is supported by proteome analysis and, to a less extent, by fatty acids analysis, two robust techniques used in bacterial taxonomy [33] and useful for characterization of Brucella [9-11,24,31,32]. Therefore, it seems that the $B$. cet $i$ isolates described here belong to a particular genotype prevalent in the Mediterranean Sea. The close relationship between Mediterranean and Atlantic B. ceti strains keeps important parallelism with the phylogenetic and taxonomical studies on the striped and bottlenose dolphin populations in both seas. Indeed, there is strong evidence of dispersal of bottlenose dolphin populations between both seas, keeping a population structure and genetic diversity in concordance with the boundaries that coincide with transitions between different habitat regions [34]. In the case of striped dolphins, there is also evidence of some genetic flow between the Mediterranean and Atlantic populations; albeit, this is significantly more restricted than in bottlenose dolphins. This is mainly due to ecological and behavioral factors that limit the exchange between these two $S$. coeruleoalba populations across Gibraltar Strait [35]. Considering this, the phenotypic and genetic structure from both North Atlantic and Mediterranean B. ceti isolates is not unexpected, as populations of $S$. coeruleoalba and T. truncatus share similar habitats and feed resources, and may then share various microorganisms, including $B$. ceti.

Infection by $B$. ceti is common in cetaceans but only a small proportion of infected cetaceans display clinicopathological signs associated to brucellosis, suggesting that many infected cetaceans overcome infection, perhaps remaining as carriers and potential Brucella shedders [5]. This is in sharp contrast with the absence of obvious disease in seals or walrus infected with $B$. pinnipedialis [36]. Several clinico-pathological entities have been associated to $B$. ceti infection in a relevant fraction of the stranded dolphins and porpoises [5], with neurobrucellosis being one of the most significant signs present $[8,12,11]$. One of our Mediterranean striped dolphins (N-301/12) presented unequivocally $B$. ceti induced non-suppurative meningoencephalitis with $B$. cet $i$ being isolated from the CNS, and regarded as the primary cause of death. This is in agreement with the suggested higher susceptibility of this dolphin species for developing neurobrucellosis in comparison to other cetaceans [12].

B. ceti has been found to invade joints and cause chronic inflammatory lesions, and has been frequently isolated from these lesions in cetaceans [10,12,37]. In line with these observations, a causal relationship was hypothesized between the discospondylitis of the peduncle observed in the bottlenose dolphin case (N-275/12) and the B.ceti strain isolated from that lesion. This discospondylitis could be causing a disabling condition, but this lesion was probably not live-threatening. Primary cause of death in this dolphin was attributed to a mycotic encephalitis caused by Cunninghamella bertholletiae.

Similarly, death of the other striped dolphin (N-372/09) was linked to CeMV-related encephalitis and not to $B$. ceti infection (isolated retrospectively only from spleen, without evidence of lesions related to Brucella). CeMV 


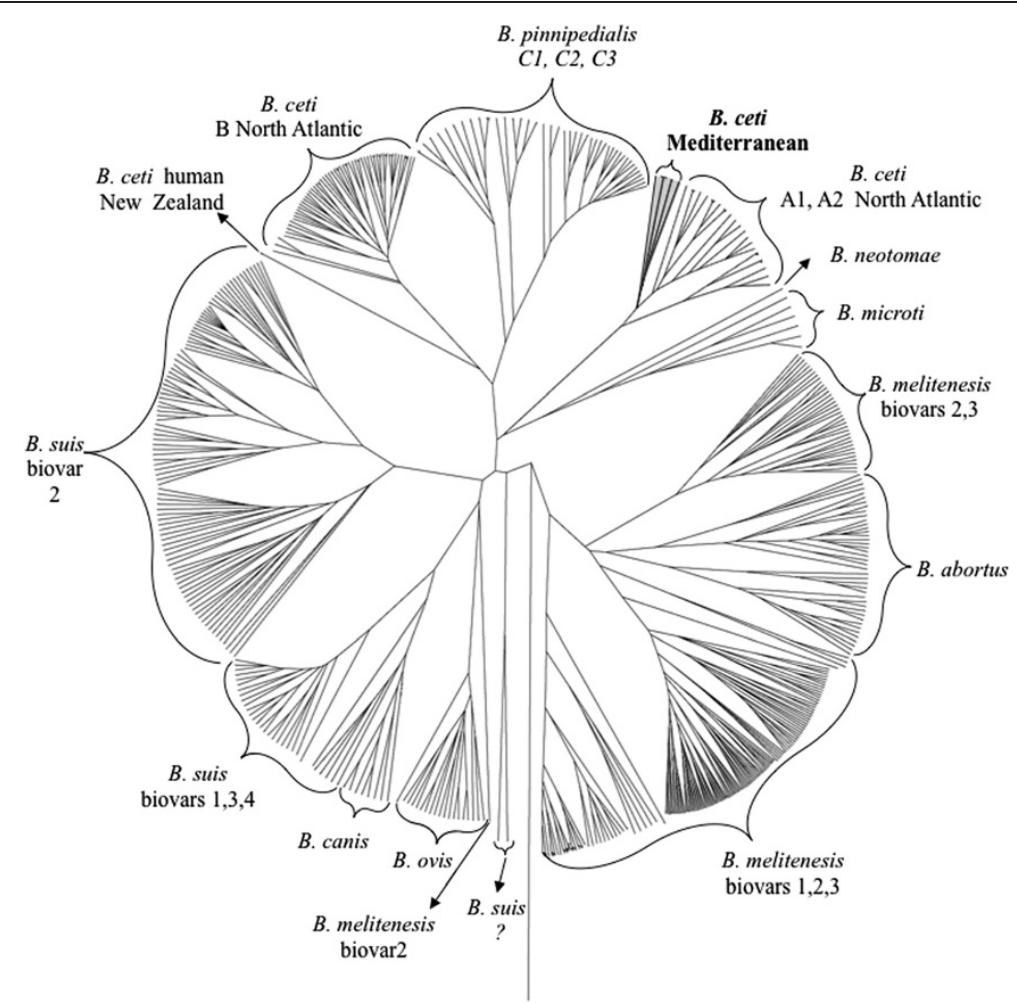

Figure 7 Brucella phylogenetic tree based on MLVA16 analysis of all the various Brucella species and strains (http://mlva.upsud.fr/ brucella/). Notice that the three Western (Spanish) and the Eastern (Italian) B. ceti Mediterranean strains cluster together in a single group (shadowed in gray) in a clade close to the Atlantic isolates (A1 and A2), all belonging to ST 26.

infections of the brain have been unambiguously linked with epizootic disease and deaths of Mediterranean striped dolphins in the past $[17,38]$.

As a corollary to these findings, it appears mandatory to establish adequate differential diagnoses for the aetiological agents that may affect disoriented livestranded dolphins. This is becoming even more relevant when a number of cetaceans in the Mediterranean Sea show a rapid decline [39], mainly due to by-catch, the presence of pollutant contamination, and the pressure of infectious diseases that threaten the health of freeranging cetaceans [40]. Brucellosis, as a contagious disease, can be an additional factor hampering the conservation efforts of cetaceans at local and global scale. Our study confirms the relevance of $B$. ceti as a cetacean pathogen in the Mediterranean, the severity of pathological signs in stranded $S$. coeruleoalba dolphins, and gives insight on the phylogenetic structure of these $B$. ceti Mediterranean isolates. The Mediterranean B. ceti strains isolated so far form a distinct phylogenetic cluster, close to that of $B$. ceti strains isolated from dolphins inhabiting the Atlantic Ocean. In addition to seriously compromising the wellbeing of marine mammals, the $B$. ceti strains possess all the current molecular virulence determinants and therefore, are potential pathogens for other animals, including humans [5].

\section{Conclusions}

B. cet $i$ has been isolated for the first time from the Spanish Mediterranean Sea, expanding the known range of this species. Neurobrucellosis with non-suppurative meningoencephalomyelitis in a striped dolphin and spondylitis in a bottlenose dolphin were the main clinicopathological features of these cases. In a third case, B. ceti was isolated from the spleen of a striped dolphin. The omp $2 b$ haplotype was common for all three $B$. ceti Mediterranean isolates and multiplex characterization showed that they were similar to the Atlantic dolphin type B. ceti B14/94 strain. Following MLVA16 analysis the three B. ceti Spanish Mediterranean strains clustered together in a distinct clade with the two reported $B$. ceti isolated in the Mediterranean Italian littorals, and close to the Atlantic A1 dolphin cluster. This taxonomical position was supported by protein and fatty acid analyses. Collecting appropriate samples for testing for Brucella has to be included in necropsy protocols in stranded dolphins. 


\section{Ethics statement}

The work did not include experimental procedures. Handling of live and dead cetaceans (species included in CITES 2 list) was done with official governmental permission. Medical treatments on live dolphins were applied following established procedures for these species.

\section{Additional files} Additional file 1: Table S1. MLVA-16 genetic profiles for the three B.
ceti isolates*.

Additional file 2: Table S2. Protein molecular weights peaks of the different Brucella strains determined by MALDI-TOF.

Additional file 3: Table S3. Fatty acids determined by gas liquid chromatography of different Brucella strains.

\section{Competing interests}

The authors declare that they have no competing interests.

\section{Authors' contributions}

FA provided veterinary treatment to live-stranded dolphins. MIA, LP, and MD performed necropsies and histopathologic examinations. LP performed immunostaining and RT-PCR for CeMV. JMB and PMM performed bacterial isolation and species identification. MB and RGB performed immunostaining for Brucella. NRV confirmed bacteriological identification of isolates received from Spain and performed MLVA analysis. CGV, CCD and ECO designed, analysed and performed lipidomics and molecular analysis of isolates and reference strains. EM designed, performed and analysed proteomics data, and integrated all results from taxonomic studies. All authors helped to draft specific parts of the manuscript. MD, EM and JMB were responsible of the design of the study and assembled the final draft of the manuscript. All authors approved the final version of the manuscript.

\section{Acknowledgements}

We thank Departament de Medi Natural from the Government of Catalonia for economical support. We thank Bruno Lomonte, Instituto Clodomiro Picado, University of Costa Rica for his assistance in the proteomic analysis. Research at the CITA is funded by INIA (RTA2011-00103-00-00), MICIN (AGL2011-30453-C04), and consolidated group A14 from Gobierno de Aragón. This work was partially funded by grants FIDA-2014 UNA, FSCONARE UNA/UCR. We wish to acknowledge M.J. de Miguel, S. Serrano, M. Uriarte, B. Pérez and A. Neira for the excellent technical assistance.

\footnotetext{
Author details

${ }^{1}$ Departament de Sanitat i Anatomia Animal, Facultat de Veterinària, Universitat Autònoma de Barcelona (UAB), and Servei de Diagnòstic de Patologia Veterinària, Facultat de Veterinària, Universitat Autònoma de Barcelona (UAB), 08193, Bellaterra, Barcelona, Spain. ²Programa de Investigación en Enfermedades Tropicales, Escuela de Medicina Veterinaria, Universidad Nacional, Heredia, Costa Rica. ${ }^{3}$ CITA Gobierno de Aragón, 50059 Zaragoza, Spain. ${ }^{4}$ Centre Fundación para la Conservación y Recuperación de Animales Marinos (CRAM), El Prat de Llobregat, Barcelona, Spain. ${ }^{5}$ Centro de Investigación en Enfermedades Tropicales, Facultad de Microbiología, Universidad de Costa Rica, San José, Costa Rica. ${ }^{6}$ Ministerio de Agricultura y Ganadería, Laboratorio de Patología, Heredia, Costa Rica. ${ }^{7}$ Instituto Clodomiro Picado, Universidad de Costa Rica, San José, Costa Rica. ${ }^{8}$ Centre de Recerca en Sanitat Animal (CReSA), UAB-IRTA, 08193, Bellaterra, Cerdanyola del Vallès, Barcelona, Spain.
}

Received: 2 March 2014 Accepted: 28 August 2014

Published online: 17 September 2014

\section{References}

1. Ewalt DR, Payeur JB, Martin BM, Cummins DR, Miller WG: Characteristics of a Brucella species from a bottlenose dolphin (Tursiops truncatus). J Vet Diagn Invest 1994, 6:448-452.
2. Foster G, Osterman BS, Godfroid J, Jacques I, Cloeckaert A: Brucella ceti sp. nov. and Brucella pinnipedialis sp. nov. for Brucella strains with cetaceans and seals as their preferred hosts. Int J Syst Evol Microbiol 2007, 57:2688-2693.

3. Foster G, Jahans KL, Reid RJ, Ross HM: Isolation of Brucella species from cetaceans, seals and an otter. Vet Rec 1996, 138:583-586.

4. Nymo IH, Tryland M, Godfroid J: A review of Brucella infection in marine mammals, with special emphasis on Brucella pinnipedialis in the hooded seal (Cystophora cristata). Vet Res 2011, 42:93.

5. Guzmán-Verri C, González-Barrientos R, Hernández-Mora G, Morales J-A, Baquero-Calvo E, Chaves-Olarte E, Moreno E: Brucella ceti and Brucellosis in Cetaceans. Front Cell Infect Microbiol 2012, 2:3.

6. Whatmore AM, Dawson CE, Groussaud P, Koylass MS, King AC, Shankster SJ, Sohn AH, Probert WS, McDonald WL: Marine mammal Brucella genotype associated with zoonotic infection. Emerg Infect Dis 2008, 14:517-518.

7. González L, Patterson IA, Reid RJ, Foster G, Barbera M, Blasco JM, Kennedy S, Howie FE, Godfroid J, MacMillan AP, Schock A, Buxton D: Chronic meningoencephalitis associated with Brucella sp. Infection in livestranded striped dolphins (Stenella coeruleoalba). J Comp Pathol 2002, 126:147-152.

8. Muñoz PM, García-Castrillo C, López-Garciá P, González-Cueli JC, De Miguel MJ, Marín CM, Barberán M, Blasco JM: Isolation of Brucella species from a live-stranded striped dolphin (Stenella coeruleoalba) in Spain. Vet Rec 2006, 158:450-451.

9. Davison NJ, Cranwell MP, Perrett LL, Dawson CE, Deaville R, Stubberfield EJ, Jarvis DS, Jepson PD: Meningoencephalitis associated with Brucella species in a live-stranded striped dolphin (Stenella coeruleoalba) in south-west England. Vet Rec 2009, 165:86-89.

10. Foster G, MacMillan AP, Godfroid J, Howie F, Ross HM, Cloeckaert A, Reid RJ, Brew S, Patterson IAP: A review of Brucella sp. infection of sea mammals with particular emphasis on isolates from Scotland. Vet Microbiol 2002, 90:563-580.

11. Alba P, Terracciano G, Franco A, Lorenzetti S, Cocumelli C, Fichi G, Eleni C, Zygmunt MS, Cloeckaert A, Battisti A: The presence of Brucella ceti ST26 in a striped dolphin (Stenella coeruleoalba) with meningoencephalitis from the Mediterranean Sea. Vet Microbiol 2013, 164:158-163.

12. González-Barrientos R, Morales JA, Hernández-Mora G, Barquero-Calvo E, Guzmán-Verri C, Chaves-Olarte E, Moreno E: Pathology of striped dolphins (Stenella coeruleoalba) infected with Brucella ceti. J Comp Pathol 2010, 142:347-352.

13. Hernández-Mora G, González-Barrientos R, Morales J-A, Chaves-Olarte E, Guzmán-Verri C, Barquero-Calvo E, Baquero-Calvo E, De-Miguel M-J, Marín C-M, Blasco J-M, Moreno E: Neurobrucellosis in stranded dolphins, Costa Rica. Emerg Infect Dis 2008, 14:1430-1433.

14. Van Bressem MF, Van Waerebeek K, Raga JA, Godfroid J, Brew SD, MacMillan AP: Serological evidence of Brucella species infection in odontocetes from the south Pacific and the Mediterranean. Vet Rec 2001, 148:657-661.

15. Garofolo G, Zilli K, Troiano P, Petrella A, Marotta F, Di Serafino G, Ancora M, Di Giannatale E: Brucella ceti from two striped dolphins stranded on Apulia coastline, Italy. J Med Microbiol 2013, 63:325-329.

16. OIE: Bovine Brucellosis. Manual of Diagnostic Tests and Vaccines for Terrestrial Animals 2013 2013, Chapter 2.4.3.

17. Soto S, González R, Alegre F, González B, Medina P, Raga JA, Marco A, Domingo M: Epizootic of dolphin morbillivirus on the Catalonian Mediterranean coast in 2007. Vet Rec 2011, 169:101-102.

18. Farrell ID: The development of a new selective medium for the isolation of Brucella abortus from contaminated sources. Res Vet Sci 1974, 16:280-286.

19. De Miguel MJ, Marín CM, Muñoz PM, Dieste L, Grilló MJ, Blasco JM: Development of a selective culture medium for primary isolation of the main Brucella species. J Clin Microbiol 2011, 49:1458-1463.

20. Alton $\mathrm{GG}$, Jones $\mathrm{LM}$, Angus RD, Verger JM: Techniques for the Brucellosis Laboratory. Paris France: INRA; 1988.

21. Mayer-Scholl A, Draeger A, Göllner C, Scholz HC, Nöckler K: Advancement of a multiplex PCR for the differentiation of all currently described Brucella species. J Microbiol Methods 2010, 80:112-114.

22. Cloeckaert A, Verger JM, Grayon M, Paquet JY, Garin-Bastuji B, Foster G, Godfroid J: Classification of Brucella spp. isolated from marine mammals by DNA polymorphism at the omp2 locus. Microbes Infect 2001, 3:729-738.

23. Le Flèche $P$, Jacques I, Grayon M, Dahouk AI S, Bouchon P, Denoeud F, Nöckler K, Neubauer H, Guilloteau LA, Vergnaud G: Evaluation and selection of tandem repeat loci for a Brucella MLVA typing assay. BMC Microbiol 2006, 6:9. 
24. Tanaka S, Suto T, Isayama $Y$, Azuma R, Hatakeyama H: Chemo-taxonomical studies on fatty acids of Brucella species. Ann Sclavo 1977, 19:67-82.

25. Dahouk Al S, Flèche PL, Nöckler K, Jacques I, Grayon M, Scholz HC, Tomaso $H$, Vergnaud G, Neubauer H: Evaluation of Brucella MLVA typing for human brucellosis. J Microbiol Methods 2007, 69:137-145.

26. Maquart M, Le Flèche P, Foster G, Tryland M, Ramisse F, Djonne B, Dahouk Al S, Jacques I, Neubauer H, Walravens K, Godfroid J, Cloeckaert A, Vergnaud G: MLVA-16 typing of 295 marine mammal Brucella isolates from different animal and geographic origins identifies 7 major groups within Brucella ceti and Brucella pinnipedialis. BMC Microbiol 2009, 9:145.

27. MLVA-NET for Brucella. http://mlva.u-psud.fr/brucella/.

28. Moreno E, Moriyón I: The Genus Brucella. In The Prokaryotes, Volume 5. Edited by Dworkin M, Falkow S, Rosenberg E, Schleifer K-H, Stackebrant E. New York: Springer Verlag; 2006:315-456.

29. Isidoro-Ayza M, Perez L, Cabanes FJ, Castella G, Andres M, Vidal E, Domingo $\mathrm{M}$ : Central nervous system mucormycosis caused by Cunninghamella Bertholletiae in a bottlenose dolphin (Tursiops Truncatus). J Wildl Dis 2014, 50:634-638.

30. Soto S, Alba A, Ganges L, Vidal E, Raga J, Alegre F, González B, Medina P, Zorrilla I, Martínez J, Marco A, Pérez M, Pérez B, Mesas A, Valverde R, Domingo M: Post-epizootic chronic dolphin morbillivirus infection in Mediterranean striped dolphins Stenella coeruleoalba. Dis Aquat Org 2011, 96:187-194.

31. Ferreira L, Vega Castaño S, Sánchez-Juanes F, González-Cabrero S, Menegotto F, Orduña-Domingo A, González-Buitrago JM, Muñoz-Bellido JL: Identification of Brucella by MALDI-TOF mass spectrometry. Fast and reliable identification from agar plates and blood cultures. PLoS One 2010, 5:e14235.

32. Brower A, Lucero N, Okwumabua O, Groussaud P, Gopaul KK, Whatmore AM, Cravero SL, Trangoni MD: Newly identified variability in Brucella canis fatty-acid content is associated with geographical origin. Epidemiol Infect 2013, 141:852-858.

33. Voorhees KJ, Jensen KR, MCAlpin CR, Rees JC, Cody R, Ubukata M, Cox CR: Modified MALDI MS fatty acid profiling for bacterial identification. J Mass Spectrom 2013, 48:850-855

34. Natoli A, Birkun A, Aguilar A, Lopez A, Hoelzel AR: Habitat structure and the dispersal of male and female bottlenose dolphins (Tursiops truncatus). Proc Biol Sci 2005, 272:1217-1226.

35. Azzolin M, Papale E, Lammers MO, Gannier A, Giacoma C: Geographic variation of whistles of the striped dolphin (Stenella coeruleoalba) within the Mediterranean Sea. J Acoust Soc Am 2013, 134:694-705.

36. Larsen AK, Nymo IH, Boysen P, Tryland M, Godfroid J: Entry and elimination of marine mammal Brucella spp. by hooded seal (Cystophora cristata) alveolar macrophages in vitro. PLOS One 2013, 8: 70186

37. Dagleish MP, BARLEY J, Howie FE, Reid RJ, Herman J, Foster G: Isolation of Brucella species from a diseased atlanto-occipital joint of an Atlantic white-sided dolphin (Lagenorhynchus acutus). Vet Rec 2007, 160:876-878.

38. Domingo M, Visa J, Pumarola M, Marco AJ, Ferrer L, Rabanal R, Kennedy S: Pathologic and immunocytochemical studies of morbillivirus infection in striped dolphins (Stenella coeruleoalba). Vet Pathol 1992, 29:1-10.

39. Maynou F, Sbrana M, Sartor P, Maravelias C, Kavadas S, Damalas D, Cartes JE, Osio G: Estimating trends of population decline in long-lived marine species in the Mediterranean Sea based on fishers' perceptions. PLoS One 2011, 6:e21818.

40. Di Guardo G, Mazzariol S, Fernández A: Biologically threatened dolphins and whales. Environ Microbiol 2011, 13:2833-2834.

doi:10.1186/s12917-014-0206-7

Cite this article as: Isidoro-Ayza et al.: Brucella ceti infection in dolphins from the Western Mediterranean sea. BMC Veterinary Research 2014 10:206

\section{Submit your next manuscript to BioMed Central and take full advantage of:}

- Convenient online submission

- Thorough peer review

- No space constraints or color figure charges

- Immediate publication on acceptance

- Inclusion in PubMed, CAS, Scopus and Google Scholar

- Research which is freely available for redistribution

Submit your manuscript at www.biomedcentral.com/submit
C Biomed Central 